\title{
Complications in Distal Radius Fracture Fixation: A Comparative Case Series
}

\section{James C Beazley ${ }^{1}$, Rory Norris ${ }^{2}$ and Andrew Mahon ${ }^{2}$}

${ }^{1}$ Department of Trauma and Orthopedics, Royal Devon and Exeter Foundation Trust, Barrack Road, Exeter, Devon, EX2 5DW, UK

${ }^{2}$ Department of Trauma and Orthopedics, University Hospitals Coventry and Warwickshire, Clifford Bridge Road, Coventry, CV2 2DX, UK

Corresponding author: James C Beazley, Department of Trauma and Orthopedics, Royal Devon and Exeter Foundation Trust, Barrack Road, Exeter, Devon, EX2 5DW, UK, Tel: +00447710988159; E-mail: jamescsbeazley@yahoo.co.uk

Rec Date: May 05, 2017, Acc Date: May 24, 2017, Pub Date: May 26, 2017

Citation: Beazley JC, Norris R, Mahon A. Complications in Distal Radius Fracture Fixation: A Comparative Case Series. Med Case Rep, 3:3.

\section{Abstract}

Aim: To compare the complication rate for 471 distal radius fracture treated with either the synthes two column plate or the DePuy distal volar radius plate (DVR) for fixation of distal radius fractures.

Methods: A retrospective study was performed by gathering data from all patients treated with internal fixation for distal radius fractures at University Hospital Coventry and Warwickshire, a level-one trauma centre, between October 2011 and April 2015. Data was collected by reviewing clinic electronic medical records and hospital logs to verify consecutive cases, fixation method, and complications. Radiographs were reviewed to identify nature of complication. The primary end point was complication directly related to plating that necessitated reoperation. Statistical analysis was performed by graph pad.

Results: Between October 2011 and April 2015, 471 patients underwent fixation of a distal radius fracture by 31 different orthopedic consultants at a level 1 trauma centre. One hundred and fifty seven distal radius fractures were treated with a Synthes 2 column plate and 314 distal radius fractures were treated with a DVR plate. The average age was 56 (15-94) years in the DVR group and 52.3 (17-91) years in the Synthes group. Fifty six percent of the Synthes 2 column plate cohort was female with $66 \%$ of the DVR cohort being female. No significant difference between complication rates existed between the two cohorts. Ten patients $(6.5 \%)$ in the Synthes cohort required a secondary procedure with $2(1.3 \%)$ suffering failure of fixation and subsequent fusion. Twenty-two patients $(7.0 \%)$ in the DVR cohort required secondary procedure, including 2 tendon ruptures $(0.6 \%)$ and one failure of fixation $(0.3 \%)$.

Conclusion: This study has shown no difference in complication rate associated with the use two commonly used distal radius fracture implants.
Keywords: Distal radius; Fracture; Internal fixation; Complications; Plate

\section{Introduction}

Distal radius fractures are common injuries with an incidence of $36.8 / 10,000$ person-years in women and $9.0 / 10,000$ person-years in men over 35 years of age [1], accounting for $18 \%$ of all fractures in the elderly population [2]. Several management options for the treatment of unstable distal radius fractures exist, including open reduction and internal fixation. The Distal Volar Radius plate (DVR) (DePuy, Leeds, UK) was the first distal radius volar locking plate brought to mass market. It was developed and popularized by Orbay [3] and introduced in 1999. Subsequent early case series showed promising result [4] leading to a rapid increase in the rate of internal fixation of distal radius fracture. Chung et al. demonstrating a 5 -fold increase in the rate of internal fixation for distal radius fractures between 1996 and 2005 in the States [5].

Given the volume of distal radius fractures and the considerable Midicare Expenditure on fixation , the number of fixed angle implants for distal radius fixation [6] has increased considerably with over twenty fixed angle implants now being available. Two of the implants with the highest volume of publications are the DVR and the $2.4 \mathrm{~mm} 2$ Column Distal Radius Plate (Synthes, Zuchwil, Switzerland). Surprisingly there is very little data in the public domain to demonstrate if there is a difference between these two implants. Whilst biomechanical data provided by Liporase et al. [7] and Levin et al. [8] showed no meaningful difference between the two implants in terms of cycles to failure and load to failure, no direct comparative clinical data exists between the plates, with cases series of each plate report a wide range of complication rates; ranging from $3.6 \%$ to $27 \%$ with the Synthes plate and $<5 \%$ to $23 \%$ for the DVR $[9,10]$.

The objective of the study was to evaluate the safety of the Synthes plate relative to the DVR at our institution, with the aim being to determine if there is a significant difference in complication rate between the DVR and Synthes cohorts. Our null hypothesis was that the rate of complications between the two groups would be the same. 


\section{Materials and Methods}

A retrospective study was performed by gathering data from all patients treated with internal fixation for distal radius fractures at University Hospital Coventry and Warwickshire, a level one trauma centre, between October 2011 and April 2015. Data was collected by reviewing clinic electronic medical records and hospital logs to verify consecutive cases, fixation method, and complications. Radiographs were reviewed to identify nature of complication. Fixation was performed via a FCR bed approach with a tourniquet and intravenous antibiotics on induction by one of 31 consultant orthopaedic surgeons. The primary end point was complication directly related to plating that necessitated reoperation. Statistical analysis was performed using t-test to determine the significance of difference in age between groups and Chi squared analysis to determine significance between groups for all other variables. Analysis performed on graph pad (La Jolla, USA).

\section{Results}

Between October 2011 and April 2015, 471 patients underwent fixation of a distal radius fracture by 31 different orthopedic consultants at a level 1 trauma centre. One hundred and fifty seven distal radius fractures were treated with a Synthes 2 column plate and 314 distal radius fractures were treated with a DVR plate. The average age was 56 (15-94) years in the DVR group and 52.3 (17-91) years in the Synthes group (Table 1). Fifty six percent of the Synthes 2 column plate cohort were female with $66 \%$ of the DVR cohort being female. Length of follow-up was 1.7 (0.5 to 2.8 ) years in the Synthes cohort and 3.9 (0.7 to 5.3 ) years in the DVR.

Table 1 Demographic details of Synthes and DVR cohorts. Chi squared test used to test significance between groups.

\begin{tabular}{|c|c|c|c|}
\hline \multirow{2}{*}{$\begin{array}{l}\text { Variable } \\
\text { s }\end{array}$} & \multirow{2}{*}{$\begin{array}{l}\text { Synthes } \\
(n=157)\end{array}$} & DVR & \multirow[t]{2}{*}{ p-value } \\
\hline & & $\begin{array}{l}(n \\
314)\end{array}=$ & \\
\hline Age & $\begin{array}{l}52.3 \\
(11-91)\end{array}$ & $\begin{array}{l}56 \\
(15-94)\end{array}$ & $p<0.05$ \\
\hline $\begin{array}{l}\text { Sex ( } \% \\
\text { female) }\end{array}$ & $56 \%$ & $66 \%$ & $p<0.05$ \\
\hline $\begin{array}{l}\text { Follow- } \\
\text { up } \\
\text { (years) }\end{array}$ & $\begin{array}{l}1.7 \\
(0.5 \text { to } \\
2.8\end{array}$ & $\begin{array}{l}3.9 \\
(0.7 \text { to } \\
5.3)\end{array}$ & $p<0.05$ \\
\hline
\end{tabular}

Table 2 sums up the complications for each group. Overall no significant difference between complication rates existed between the two cohorts. Ten patients (6.5\%) in the Synthes cohort and twenty-two patients $(7.0 \%)$ in the DVR cohort required secondary procedures.

Table 2 Complications the complication profile for both cohorts are shown above. No significant difference in complication rates or type was observed between the two cohorts.

\begin{tabular}{|c|c|c|c|}
\hline Indication for readmission/reoperation & Synthes & DVR & NS \\
\hline & $\begin{array}{l}N=10 \text { of } 157 \\
-6.30 \%\end{array}$ & \multicolumn{2}{|c|}{$N=22$ of $314(7.0 \%)$} \\
\hline Removal of plate for pain and stiffness in absence of collapse & $4(2.5 \%)$ & $10(3.1 \%)$ & NS \\
\hline Revision for collapse/loss of reduction & $3(1.9 \%)$ & $1(0.3 \%)$ & NS \\
\hline MUA without removal plate & $1(0.6 \%)$ & $1(0.3 \%)$ & NS \\
\hline Arthroscopy for ongoing pain and stiffness & $1(0.6 \%)$ & 0 & NS \\
\hline Debridement for infection & $1(0.6 \%)$ & $1(0.3 \%)$ & NS \\
\hline Carpal tunnel syndrome & 0 & $6(1.9 \%)$ & NS \\
\hline Extensor tendon rupture & 0 & $2(0.6 \%)$ & NS \\
\hline TFCC injection & 0 & $1(0.3 \%)$ & NS \\
\hline
\end{tabular}

Loss of fixation was observed in three patients (1.4\%) in the Synthes cohort and one patient $(0.3 \%)$ in the DVR cohort. This difference was not found to be statistically significant. The single loss of fixation in the DVR cohort (Figure 1) was as a result of loss of fixation in the shaft. In contract, the three cases of loss of fixation in the Synthes patients were due to loss of fixation distally or collapse of distal fragments and screw penetration (Figure 2). A post hoc power analysis suggested that 724 patients would be required in each group to have an $80 \%$ chance of detecting a difference in loss of fixation rate.
Four patients $(2.5 \%)$ in the Synthes cohort and 10 patients (3.1\%) in the DVR cohort required removal of plate as a result of ongoing pain and stiffness following union of fracture but with no collapse noted. Two patients $(0.6 \%)$ in the DVR cohort suffered an extensor pollicis longus tendon rupture, both of which were treated with tendon transfer and made a good recovery. Six patients $(1.9 \%)$ in the DVR cohort underwent a carpal tunnel decompression with no carpal tunnel decompressions required in the Synthes cohort $(P>0.05)$. 

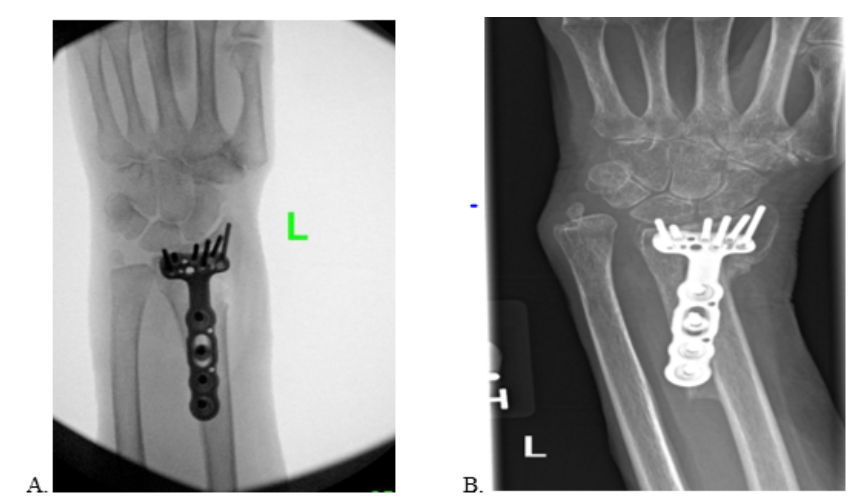

Figure 1 Single case of loss of fixation DVR. Loss of fixation of shaft in a 76 year-old female note 3 months post implantation of DVR.
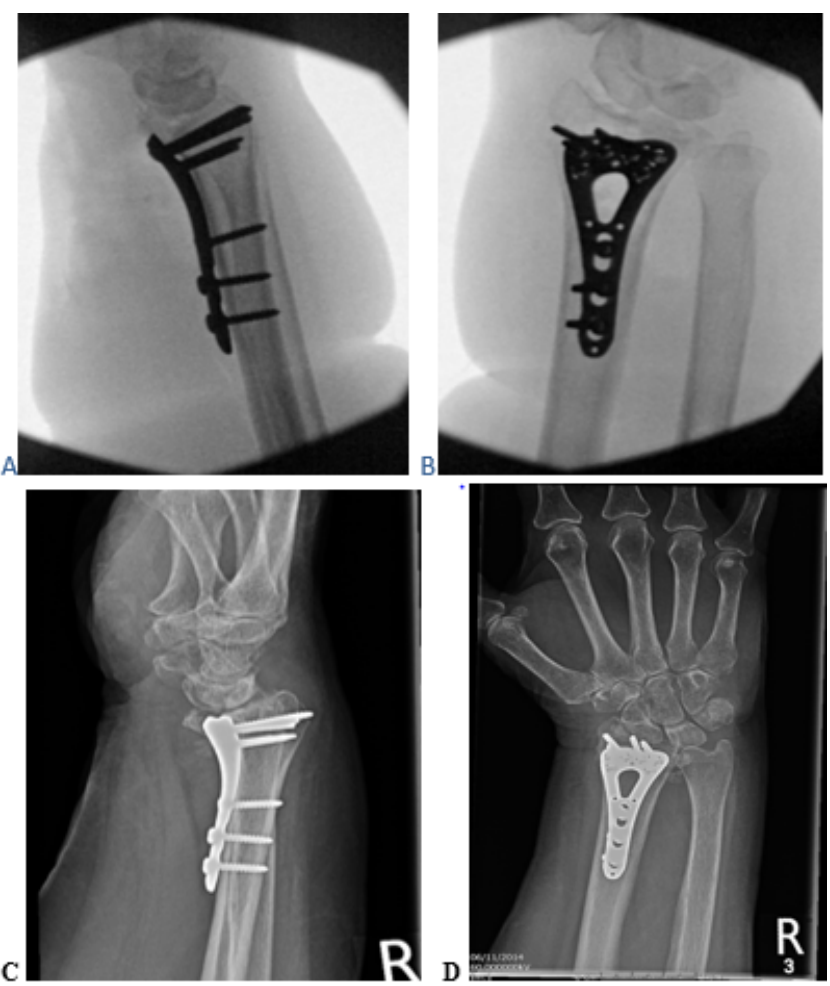

Figure 2 One of three cases of Synthes plates revised for loss of reduction. Loss of fixation of lunate fossa fragment in a 69-year-old female that resulted in revision to radiolunate fusion.

The complication profile for both cohorts is shown above. No significant difference in complication rates or type was observed between the two cohorts.

To eliminate length of follow-up as a confounding variable we looked at re-operation within one year and found no significant difference between the two cohorts. The Synthes plate complication rate within one year was $4.5 \%$ whilst the DVR plate complication rate within the year was $5.4 \%(p=0.82$ Chi squared).

\section{Discussion}

With increasing financial constraints within healthcare systems there is pressure to change implant type to save money. It is striking how little data there is in the public domain to help guide our choice of trauma implant and evaluate the safely of any such change. This is the first study directly comparing the complication rate of two commonly used distal radius plates. Our observed complication rate for both implants was well within the rates described in the literature [9-12].

\section{Conclusion}

Although the mechanism of plate failure was observed to be different between the two cohorts, we observed no significant difference in complication rate between the Synthes and DVR cohorts. We do appreciate this is a retrospective study and subtle differences exist between the cohorts which may introduce an element of bias. This bias is however more likely to introduce type one error, which was not observed. As such this study suggests there is no significant difference in complication rate between uses of the DVR or Synthes 2 column plates.

\section{References}

1. O'Neill TW, Cooper C, Finn JD, Lunt M, Purdie D, et al. (2001) Incidence of distal forearm fracture in British men and women. Osteoporos Int 12: 555-558.

2. Kwan K, Lau TW, Leung F (2011) Operative treatment of distal radial fractures with locking plate system-a prospective study. Int Orthop 35: 389-394.

3. Orbay JL (2000) The treatment of unstable distal radius fractures with volar fixation. J Hand Surg 5: 103-12.

4. Orbay JL, Fernandex DL (2000) Volar fixation for dorsally displaced fractures of the distal radius: a preliminary report. J Hand Surg Am 27: 205-215.

5. Chung KC, Shauver MJ, Birkmeyer JD (2009) Trends in the United States in the treatment of distal radial fractures in the elderly. $J$ Bone Joint Surg Am 91: 1868-1873.

6. Shauver MJ, Yin H, Banerjee M, Chung KC (2011) Current and future national costs to Medicare for the treatment of distal radius fracture in the elderly. J Hand Surg Am 36: 1282-1287.

7. Liporace FA, Kubiak EN, Jeong GK, lesaka K, Egol KA, et al. (2006) A biomechanical comparison of two volar locked plates in a dorsally unstable distal radius fracture model. J Trauma 61: 668-672.

8. Levin SM, Nelson CO, Botts JD, Teplitz GA, Kwon Y, et al. (2008) Biomechanical evaluation of volar locking plates for distal radius fractures. Hand 3: 55-60.

9. Wichlas F, Haas NP, Disch A, Machó D, Tsitsilonis S (2014) Complication rates and reduction potential of palmar versus dorsal locking plate osteosynthesis for the treatment of distal radius fractures. J Orthop Traumatol 15: 259-264.

10. Arora R, Lutz $M$, Hennerbichler A, Krappinger D, Espen D, et al. (2007) Complications following internal fixation of unstable 
distal radius fracture with a palmar locking-plate. J Orthop Trauma 21: 316-322.

11. Fok MW, Klausmeyer MA, Fernandez DL, Orbay JL, Bergada AL (2013) Volar plate fixation of intra-articular distal radius fractures: A retrospective study. J Wrist Surg 2: 247-254.
12. Ward CM, Kuhl TL, Adams BD (2011) Early complications of volar plating of distal radius fractures and their relationship to surgeon experience. Hand 6: 185-189. 